\title{
Vinculo: um conceito problemático no campo da Saúde Coletiva
}

| ${ }^{1}$ Maria Idalice Silva Barbosa, ${ }^{2}$ Maria Lúcia Magalhães Bosi |

Resumo: A relação entre os profissionais e as pessoas que usam os serviços de saúde é um tema importante no âmbito do SUS e adquire uma linguagem especial na Política Nacional de Atenção Básica (PNAB) pelo uso da palavra vínculo.

O objetivo deste artigo é focalizar a dimensão semântica do uso do termo "vínculo" em Saúde Coletiva, revisando pesquisas e textos oficiais da política setorial que o incluem em seus descritores ou o apontam como relevante em seus resultados. Selecionamos 52 artigos nas bases Lilacs e SciELO, incluindo nos campos assunto ou título a palavra "vínculo", associando-a aos descritores: Atenção Primária à Saúde, Atenção Básica à Saúde, Sistema Único de Saúde, Saúde da Família, Estratégia Saúde da Família, Saúde Coletiva, Saúde Pública. Concluímos que, apesar de os estudos aludirem ao termo/conceito constatando sua inequívoca importância no campo da saúde, o vínculo quase sempre é algo não visto, mas que deveria existir como condição para funcionamento do serviço em termos de responsabilização e longitudinalidade do cuidado. Este lugar de invisibilidade certamente não significa o lugar da não existência, mas da precariedade teóricometodológica concernente a concepçóes e desenhos de pesquisas que tocam fenômenos relacionais tão complexos quanto este no campo da Saúde Coletiva.

> Palavras-chave: Saúde Coletiva; vínculo; Atenção Primária em Saúde.
1 Universidade Federal do Ceará, Departamento de Saúde Comunitária. Fortaleza-CE, Brasil (idaliceb@gmail.com)

${ }^{2}$ Universidade Federal do Ceará, Departamento de Saúde Comunitária. Fortaleza-CE, Brasil (malubosi@pq.cnpq.br). 
A relação entre os profissionais e as pessoas que usam os serviços de saúde é um tema importante no âmbito do SUS e adquire uma linguagem especial na atenção básica pelo uso da palavra vínculo. (BRASIL, 2012) A Política Nacional de Atenção Básica (PNAB) tem como foco adscrever usuários e desenvolver relaçôes de vínculo e responsabilização entre equipes e população. Segundo suas diretrizes, a atenção básica deve funcionar como porta de entrada e centro de comunicação de toda a rede de atenção com um amplo espectro de ações: promoção de saúde; prevenção de agravos; diagnóstico; tratamento; reabilitação; redução de danos e manutenção da saúde.

Para a PNAB, vínculo "consiste na construção de relaçôes de afetividade e confiança entre o usuário e o trabalhador da saúde, permitindo o aprofundamento do processo de corresponsabilizaçáo pela saúde, construído ao longo do tempo, além de carregar, em si, um potencial terapêutico" (BRASIL, 2012, p. 21). A política enquadra o vínculo como condicionante de sua efetivação, uma vez que o apresenta como viabilizador da corresponsabilidade, continuidade e longitudinalidade do cuidado.

Neste artigo, nossa intenção é focalizar a dimensão semântica do uso do termo "vínculo" no campo da Saúde Coletiva, revisando pesquisas que incluem essa palavra entre seus descritores ou o apontam como relevante em seus resultados. Para tanto, selecionamos artigos buscando nas bases Lilacs e SciELO, haja vista a representatividade dessas bases para o campo em questáo, associando a palavra vínculo aos descritores: Atenção Primária à Saúde (APS); Atenção Básica à Saúde; Sistema Único de Saúde; Saúde da Família; Estratégia Saúde da Família; Saúde Coletiva; Saúde Pública. Selecionamos artigos que incluíam quaisquer dos descritores mencionados nos campos assunto ou título, localizando 52 trabalhos que tocavam a dimensão do vínculo na atenção em saúde (vide quadro 1)

Dentre os 52 estudos localizados, identificamos dois trabalhos que se propóem a fazer uma revisão de literatura abordando vínculo. A primeira publicação (SCHIMITH et al., 2011) tem como fonte as bases de dados Lilacs e Pubmed, com recorte temporal de 20 anos (1990 e 2010), caracterizando-se como "revisão integrativa". O estudo constata que a produção brasileira comparada à internacional centra-se no hospital como campo de investigaçáo. Segundo os autores, o campo das práticas em saúde é ainda organizado e efetivado, 
predominantemente, segundo uma visão biologicista e fragmentada dos serviços,

e a transformação das práticas depende de um reconhecimento do usuário como sujeito do processo de saúde, por parte dos profissionais. Em relação, especificamente, ao termo "vínculo", o estudo conclui que este é fundamental para tomada de decisão compartilhada, e essencial para adesão e continuidade do tratamento.

O segundo estudo (BRUNELLO et al., 2010), caracterizado também como uma revisão sistemática na literatura, volta-se, especificamente, para as produções brasileiras e possui recorte temporal de dez anos (1998-2007). Utilizou as bases Lilacs e SciELO pesquisando, entre seus descritores, a palavra vínculo. Os autores afirmam que o interesse pelo tema vem sendo impulsionado no Brasil pelo advento das políticas de humanização em saúde. Em suas conclusóes, apontam que o vínculo teria uma tendência de melhorar o conhecimento sobre os "reais problemas da população", e também o relacionamento entre profissionais e usuários.

Tanto as pesquisas que revisam o tema vínculo na literatura, como os textos das políticas consultados demonstraram a relevância do vínculo para atenção à saúde, apontando ainda para a necessidade de reconhecimento do outro como sujeito de direitos. Cabe ressaltar que dos 52 trabalhos localizados, apenas dois abordam o termo conceitualmente. Os demais o apresentam em justaposição com outras palavras, como, responsabilizaçâo, acesso, autonomia, longitudinalidade, acolhimento sem fazer qualquer distinção entre os termos da investigação pretendida. Em função dessa relevância atribuída ao vínculo e da lacuna relativa a sua demarcação conceitual, propomo-nos neste artigo tecer uma análise crítica da utilização do termo no campo da Saúde Coletiva, mediante uma problematização de seu uso em termos conceituais.

\section{Vínculo como tema de pesquisa em Saúde Coletiva}

Em uma primeira análise geral do material discursivo selecionado (artigos e textos oficiais da política setorial), ressaltamos alguns pontos relevantes. Observamos, inicialmente, que o uso do termo "vínculo" é conotado ora como um dispositivo, seja de atenção integral à saúde, seja do cuidado; ora como tecnologia relacional, ferramenta relacional, instrumento de trabalho relacional, e/ou, ainda, como "tecnologia leve", fazendo referência à caracterização feita por Merhy (2005), quando a diferencia das tecnologias duras e leves-duras. 
No geral, a literatura aborda o vínculo formando uma espécie de amálgama semântico com outras palavras, sempre escritas lado a lado, a depender da temática do estudo em questão. Assim, encontramos investigaçôes que abordam: acesso-acolhimento-vínculo; acolhimento-vínculo-responsabilização; acolhimento-vínculo-diálogo; responsabilização-vínculo-autonomia; acessoacolhimento-vínculo-responsabilização; acolhimento-vínculo-acesso, longitudinalidade-vínculo-autonomização. $\mathrm{O}$ uso do hífen não é utilizado nos artigos, contudo, o empregamos aqui para esboçar o sentido de amálgama semântico que cada estudo insere o vínculo. Os estudos apenas empregam estes termos de forma conjunta, sem aludir a diferenciaçôes entre eles, compreendendoos como ferramentas, dispositivos ou tecnologias. Além disso, não apresentam justificativas ou reflexôes que elucidem a associação de tais conceitos, tampouco os motivos da inserção do vínculo humano no rol das ferramentas.

Constatamos que, comumente, termos que se referem ao campo das relaçôes humanas no âmbito da saúde são aludidos como ferramenta, tecnologia, instrumento ou dispositivo relacional, sendo este o âmbito em que se inscreve a palavra vínculo. Ora, causa certa estranheza o uso de palavras que aludem ao campo subjetivo relacional serem conotadas pertencendo ao rol das ferramentas. $\mathrm{Na}$ maioria das vezes, tais palavras aludem a objetos usados no trabalho, algo que precisamos como meio para um determinado fim. No campo da saúde, uma ferramenta pode ser um estetoscópio que se usa para determinada finalidade; um instrumento pode ser uma caneta, maca etc. Mas de que forma podemos equiparar termos/conceitos como autonomia, vínculo, acolhimento, responsabilização, entre outros, como ferramentas? Certamente há um problema importante que merece ser examinado com mais profundidade concernente à propriedade de o vínculo humano, próprio do campo relacional, poder ser compreendido como ferramenta, ou seja, um meio para se alcançar determinado fim, indicando um uso instrumental de algo que ontologicamente resiste a essa apropriaçáo.

Um segundo ponto que destacamos nesta análise inicial, e que nos parece de importância central, refere-se ao próprio uso do termo "vínculo" aludido de forma bastante reducionista e, o que é mais grave, sem lastro conceitual. Comumente, vínculo é confundido ou reduzido a um simples contato, qualquer que seja, por meio de consultas, grupos, visitas domiciliares, momento em que acontece algum encontro - entendido no sentido igualmente reduzido do temo - entre 
profissionais de saúde e as pessoas que usam os serviços de Atenção Primária à Saúde (APS). Vale ressaltar que esse contato é sempre referido como algo que favorece, ou o momento em que se "cria o vínculo". Constatamos também de maneira recorrente que o vínculo é utilizado como sinônimo da palavra confiança, sem tecer argumentos que permitam tal caracterizaçáo. Um terceiro aspecto que nos sobressaiu nesta primeira análise geral do material foi o vínculo ser, de forma recorrente, apresentado como condição para algo ou alguma coisa. Assim, vínculo se apresenta como condição para a autonomia, para a longitudinalidade do cuidado, para a responsabilização, para a confiança.

Esta condicionalidade é apresentada quando os textos trazem reflexóes aludindo ao vínculo como algo que ora favorece, ora facilita, ora amplia, cria e fortalece "quase tudo" no serviço da APS. Esse "quase tudo" se refere aos temas nos quais se detêm as investigaçôes. Assim, quando o artigo aborda aspectos relacionados à gestão da APS, o vínculo é apontado como condicionante para uma boa prestação de serviço; se abordam programas da APS, seja referindo-se às terapêuticas ou à adesão dos pacientes, o vínculo novamente é a condição para isso; se o estudo se reporta às açôes de promoção e educação em saúde, as conclusóes apontam ser o vínculo a condição determinante, tanto para que haja tais práticas como para o sucesso e o resultado delas.

Em relação a esse aspecto condicionante do vínculo para esse "quase tudo" nos serviços da APS, percebemos que, no geral, as pesquisas chegam a essa conclusão, ora por um viés positivo, quando se aponta a presença do vínculo como algo que favorece esse "quase tudo", ora por um viés negativo, quando esse "quase tudo" se encontra fragilizado, apontando como conclusáo o fato de que isso acontece em função de uma suposta ausência deste vínculo, que não fora criado.

Esclarecemos, todavia, que mesmo quando se refere a um viés positivo, o tempo verbal utilizado para indicar a presença do vínculo é o futuro do pretérito, ou seja, na forma de um dever ser normativo, hipotético. O vínculo, então, acaba sempre referido em alusão a uma ausência pressuposta, hipótese, incerteza ou irrealidade congruente com o emprego do futuro do pretérito. Portanto, seja na via positiva ou negativa, o vínculo é apontado como algo supostamente ausente, algo não visto, ou ainda um dever ser.

Após esta análise geral concernente ao uso do conceito, empreendemos uma segunda análise focalizando esse "quase tudo" que condiciona, favorece, fortalece, 
amplia o vínculo. Construímos, a partir da literatura examinada, sete categorias centrais com as quais a palavra vínculo se relaciona, adiante desdobradas: gestão dos serviços da atenção básica, ações específicas da atenção básica, assistência terapêutica, participação e democratização dos serviços, competência/formação profissional e práticas educativas na APS. Percebemos, para cada categoria, uma extensa lista de aspectos, com os quais a literatura associa vínculo, ora em seu viés positivo, ora no negativo, na acepção aqui adotada.

Apresentamos a seguir a categorização, esclarecendo que, para cada uma das categorias construídas a partir dos textos, a análise dos textos pressupóe ambos os vieses positivo ou negativo. A diferença denota apenas o modo como a pesquisa referencia o termo, pela suposta presença ou ausência do vínculo. Reiteramos ainda que a via positiva não caracteriza a presença do vínculo como algo que favorece isso ou aquilo, mas no geral ressalta um dever ser normativo. Para evitar repetiçóes, a leitura abaixo pressupóe ambos os sentidos, tanto positivo como negativo, de forma que o vínculo é apresentado como algo que favorece ou favoreceria, evita(ria), contribui(ria), aumenta(ria), melhora(ria) o que refere cada categoria relacionada às distintas açôes ou serviços da APS.

\section{Gestão dos serviços da Atenção Básica}

Agrega estudos relacionados à melhoria da gestáo dos serviços de saúde na atençáo básica concernentes à: participação, eficácia de açôes, acesso, resolutividade etc. Os estudos referem o vínculo como algo que: favorece(ria) a gestáo participativa; evita(ria) açôes desnecessárias; contribui(ria) para eficácia das açóes em saúde; aumenta(ria) a resolutividade dos serviços e/ou programas (Saúde Mental, Saúde do Trabalhador, Saúde do Adolescente, Acompanhamento de pacientes com TB, HA, Dia, Pré-natal, Programa Família Saudável etc.); melhora(ria) o acesso aos serviços; Diminui(ria) a rotatividade de profissionais médicos e enfermeiros na ESF; Favorece(ria) o uso racional de medicamentos.

\section{Açóes da Atenção Primária em Saúde}

São estudos que trazem outra nuance, afastando-se da categoria acima, e ressaltam as açôes próprias deste nível de atenção, apresentando o vínculo como condição para sua efetivação. O vínculo favorece(ria): açôes de promoção de saúde; açooes 
intersetoriais; formação de grupos; intervençôes coletivas; visita domiciliar; capacitaçóes em geral na comunidade (oficina e cursos os mais diversos).

\section{Assistência}

Reúne os estudos que se referem às práticas de assistência. $O$ vínculo é visto como algo que contribui(ria) para melhorar, tem (ou teria) efeitos de correlação positiva no(a): acolhimento; atendimento humanizado; responsabilização; autonomia; clínica ampliada; abordagem e cuidados de vítimas da violência doméstica; dá permissão para que o profissional supra as necessidades, intervenha, aconselhe, partilhe opinião, promova suporte psicológico para alívio da ansiedade.

\section{Terapêutica}

Refere-se à terapêutica ligada à assistência e apresenta pesquisas que abordam a adesão aos diversos programas próprios dos pacotes da atenção básica. Em todos eles, o vínculo é referido como algo condicionante da adesão das pessoas e, no caso, aumenta(ria) ou melhora(ria) a adesão à terapêutica e/ou a continuidade do tratamento; adesão aos programas (Tuberculose, Hipertensão, Diabetes, Prénatal, às açôes de promoção de saúde etc.); acompanhamento de recém-nascidos de baixo peso; confiança entre profissionais e usuários.

\section{Participação e democratização dos serviços}

São estudos específicos sobre gestáo participativa no SUS e avaliam práticas na atenção básica, apresentando o vínculo como algo condicionante para o fomento de práticas como: cidadania, participação da comunidade e a criação de espaços de convivência.

\section{Competência/Formaçáo Profissional}

Congrega estudos sobre a competência e a formação profissional para atenção básica e aponta o vínculo como condicionante no sentido de favorecer o aprendizado, ou mesmo a prática profissional na atenção básica no tocante à competência profissional e à atividade clínica. $\mathrm{O}$ vínculo é referido ainda em estudos relacionados ao currículo de formação da medicina, no que diz respeito ao avanço de um currículo integrado, cuja efetivação supostamente favorece(ria) o vínculo. 


\section{Práticas Educativas na Atenção Básica}

Agrega estudos que relacionam o vínculo às metodologias utilizadas nas práticas educativas da atençáo básica, ressaltando que o uso de metodologias tradicionais não favorece(ria) o vínculo.

Estas categorias nos permitem afirmar uma compreensão geral do vínculo no discurso da Saúde Coletiva como algo que condiciona "quase tudo" nos serviços da APS, tornando-o algo para o qual tudo converge ou deva convergir.

Uma imagem que facilita um entendimento do que queremos expressar é uma espécie de vórtice, algo que gira em torno de si mesmo, e para o qual tudo converge, e não se sabe o que causa a força centrípeta. Tudo que trata de assuntos relacionais converge para a palavra vínculo. Essa imagem revela também um reconhecimento da sua importância no âmbito da atenção básica, mesmo que seu significado seja tão nebuloso, considerando esse poder de

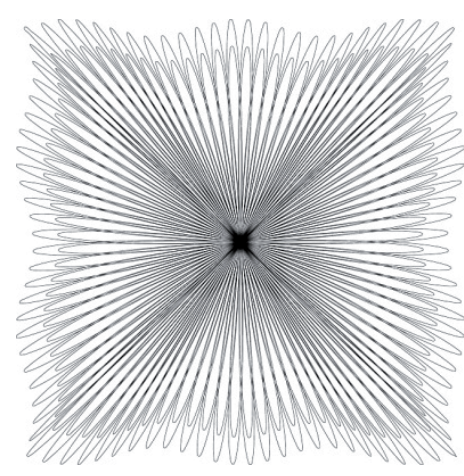

Vórtice geométrico convergência.

A literatura é escassa em abordar vínculo em termos teórico-conceituais, conforme já referido. Sua expressão como amálgama semântico dificulta e/ou escamoteia conceituaçóes, já que opera com o uso de sinônimos, quase sempre referindo confiança, elo, relação interpessoal estreita. Além disso, não se observa um refinamento capaz de diferenciar, por exemplo, de vínculo terapêutico, vínculo de amizade, vínculo profissional, ou mesmo vínculo institucional.

Em termos gerais, essas pesquisas, ao abordar o vínculo, articulado ou não a outros aspectos próprios da APS, formando o amálgama semântico referido anteriormente, buscam responder questóes a respeito de como esta ou aquela política tem se efetivado no âmbito dos serviços, ou de que forma este ou aquele conceito está presente em determinado serviço, podendo ser qualificado ou enquadrado, por exemplo, como integral, ou humanizado no sentido do "acolhimento-vínculo-responsabilização-acesso-longitudinalidade-autonomia", tal como preconiza um ou outro discurso da política oficial, e ou construto teórico que a fundamenta. 
Há raras exceçôes a esse padrão e, entre todos os estudos examinados, encontramos apenas dois que apresentam um esforço de conceituação, e que, por esse motivo, passamos a comentar.

O primeiro é uma pesquisa que, apesar de inserir o vínculo em amálgamas semânticos, apresenta um conceito para se referir ao termo. A pesquisa apresenta como objetivo compreender a utilização do acolhimento, vínculo e a corresponsabilização na construção do cuidado direcionado aos usuários com hipertensão arterial. Os autores assim definem vínculo: "um instrumento relacional que permite a circulação de afetos entre pessoas, além de se constituir em ferramenta eficaz na horizontalização e democratização das práticas de cuidado, pois favorece a negociação entre os sujeitos envolvidos nesse processo" (LIMA; MOREIRA; JORGE, 2013, p. 515, grifos nossos).

Esta definição de Lima, Moreira e Jorge (2013) é feita pelos autores, reportando-se a outro estudo (SILVA JÚNIOR; MASCARENHAS, 2004). Nesse estudo a que os autores se reportam, por sua vez, seus autores apresentam, inicialmente, a definição de vínculo do dicionário Aurélio: "tudo que ata, liga ou aperta; ligação moral; relação", e mais à frente recorrem a uma definição apresentada por Chakkour, da seguinte forma:

Chakkour (2001, p. 6), a partir de Pinchon-Rivière (1982), conceituou vínculo como "o desenvolvimento de circularidade de afetos entre trabalhador e usuários, construindo a interaçáo entre duas pessoas, criando uma maneira particular de se relacionarem, a cada caso e a cada momento" (SILVA JÚNIOR; MASCARENHAS, 2004, p. 248).

Éa partir da definição apresentada por Chakkour, que, por sua vez, fundamentase em Pichon-Rivière (2007), que os autores do estudo em questão, Silva Júnior e Mascarenhas (2004), propõem-se pensar o vínculo em três dimensões: afetividade; relação terapêutica e continuidade. Importante esclarecer que a afetividade no estudo se refere náo à relação entre profissional e a pessoa que utiliza o serviço, mas trata do gosto que o profissional deve(ria) ter em relação a sua profissão, e, em decorrência disso, desenvolver um interesse pela pessoa do paciente, e só assim construir um vínculo firme e estável que se torne um valioso instrumento de trabalho. Já a dimensâo terapêutica está ligada ao ato de dar atenção, uma nova forma de cuidado, e para expressar isso, o autor se apoia em Boff (2004), que defende o cuidar como atitude, numa relação de interaçáo e convivência, zelo e desvelo. $\mathrm{O}$ artigo destaca ainda diversas publicaçóes ligadas à corrente de atenção 
centrada no paciente, quando enfatiza a potência do vínculo para a compreensão do sofrimento e aponta a relação profissional/paciente como fundamental para as intervençôes e uma maior adesão tanto à terapêutica, quanto às medidas de prevenção e promoção. A terceira dimensão, a continuidade, é compreendida pelos autores como a responsabilização que o profissional deve assumir em relação à vida e morte do paciente, salvaguardadas as devidas possibilidades de intervenção (SILVA JÚNIOR; MASCARENHAS, 2004).

Analisando estas três dimensões a partir das quais os autores analisam o vínculo, elas se caracterizam como um apelo-exortação para um dever ser; expressam fatores que condicionam o vínculo, exortando que o profissional deve(ria) gostar da sua profissão, para, então, ser possível assumir uma postura de cuidado que expresse uma atitude de compreensão, empatia e se responsabilize pela vida e morte de quem cuida, guardando as devidas limitaçóes de contexto.

Percebemos com isso que o estudo pressupóe um pano de fundo que, de certa forma, justificaria posturas de distanciamento entre os profissionais e os pacientes, sendo isso explicado pela falta de gosto do profissional em relação à profissão que escolheu. É interessante ressaltar que a dimensão afetiva implicada no conceito é centrada no profissional, e só depois direcionada à pessoa que está sob seus cuidados. A afetividade fica condicionada ao dever ser por parte do profissional, isto é, se tal dever não se esboça, não é possível o interesse do profissional em relação à pessoa que cuida e, por consequência, não haveria vínculo. E se isso não ocorre, estaria presumivelmente justificado, em função de uma não identificação do profissional com sua profissão, explicado, talvez, por uma suposta não circulação do afeto. Fica claro que os aspectos relativos à compreensão da relaçáo entre afetividade e vínculo merecem ser problematizados em termos conceituais.

Percebemos que, de acordo com a análise dos autores, um elemento-chave do conceito vínculo está ligado ao afeto, sendo o vínculo algo que supostamente permite que o afeto circule, para, então, ser uma ferramenta eficaz nas práticas de cuidado. A partir desta compreensão, os autores parecem assumir que sem o vínculo, o afeto provavelmente estagnaria, ficando impedido de circular. Aqui é importante questionarmos: de que forma o vínculo faz circular o afeto entre as pessoas? Pensar em vínculo como condição de "circulação de afeto" nos leva a pensar em "afetos estagnados", levantando a questão sobre o que seria um afeto que circula e um afeto que não circula. Por outro lado, não seria razoável pensar 
também que o próprio afeto favoreceria o vínculo? Que relação realmente há entre vínculo e afeto?

Por fim, esta definição suscita perguntas que demonstram uma fragilidade conceitual, sem contar que se utiliza de uma definição citando um autor, que, por sua vez, cita um outro, que se referencia, ainda, em outro autor. $\mathrm{O}$ conceito é, pois, referendado por citação de citação, sem nenhuma preocupação com o conceito original embasado na Teoria do Vínculo Patológico, do psiquiatra argentino Pichon-Rivière (2007), cuja formulação original necessita reflexões ao ser trasladada ao campo da Saúde Coletiva.

O segundo estudo (BERNARDES; PELLICCIOLI; MARQUES, 2013), que apresenta uma conceituação para vínculo, entre os que localizamos, teve como objetivo analisar o vínculo como estratégia de cuidado no âmbito das políticas de saúde. Amparado nas proposiçóes de Foucault, tece reflexóes sobre o modo de vinculação das políticas, ou seja, na forma de relação entre governo e sociedade na micropolítica da vida cotidiana. Os autores concebem vínculo como "um foco de experiência constituído pela correlação entre formação de saberes, normatividade de comportamentos e formas de subjetivaçáo no que diz respeito a uma pragmática do sujeito em suas diferentes modalidades de relação consigo mesmo" (BERNARDES; PELLICCIOLI; MARQUES, 2013, p. 2.339).

Os autores do estudo enquadram a atenção básica como o primeiro contato da população com o sistema de saúde, ressaltando a criação de um escopo de açóes, cujas formas de intervenção se voltam não mais para as práticas tecnológicas, e sim para os requisitos necessários que tornam tais intervenções possíveis, isto é, o vínculo. A saúde, doravante, é que migra até o sujeito, e não mais o contrário, como nas tecnologias hospitalares. Segundo a análise dos autores, o vínculo entre o setor saúde e a população adquire outra conotação em sua mediação de poder entre estado/sociedade. Isso significa dizer, segundo eles, que o vínculo sairia de uma regiáo de interioridade do sujeito, passando a ser condição básica para o estabelecimento de formas de cuidado, sendo as estratégias vinculatórias pensadas em detrimento das terapêuticas. Disso resultaria uma capilarização da governabilidade biopolítica que chega ao nível da vida cotidiana, quando focaliza o vínculo que se deveria construir entre população e serviços de saúde, tendo nas práticas de cuidado um instrumento privilegiado para o exercício de poder, cada vez mais descentralizado e sutil, arrematam os autores. 
Esta perspectiva situa o vínculo tão somente nas relaçôes de poder entre estado/sociedade. Apesar de ser um aspecto importante relacionado ao tema, tendo em vista o exercício da cidadania e o acesso ao direito à saúde, acaba sendo uma perspectiva reducionista, e quando confrontada com o contexto da atenção básica, apresenta algumas inconsistências. Por exemplo, quando os autores afirmam que na atenção básica as estratégias vinculativas são pensadas em detrimento das terapêuticas, algo soa estranho em função mesmo da ausência do vínculo bastante aludida pelos pesquisadores. Ora, como vimos, as pesquisas, mesmo quando destacam o vínculo como um dispositivo, ferramenta, mesmo em amálgama com outros conceitos, como longitudinalidade, responsabilização, constatam o vínculo supostamente ausente, comprometendo a efetividade dos serviços na APS. O pressuposto de que as estratégias vinculativas são pensadas em detrimento das terapêuticas não se sustenta, mesmo ante a fragilidade conceitual em que ainda se encontra o uso deste conceito na literatura.

Um último aspecto que ressaltamos relacionado aos estudos elencados é que, em sua maioria, são investigaçóes que se propóem perceber até que ponto este ou aquele conceito, todos aludidos em conjunto (vínculo, responsabilização e autonomia), foram incorporados ou não pelos profissionais. A questão que se coloca é pensar o que significa esta incorporação de que fala os autores. Do que se fala quando se afirma que tal ou tal coisa foi incorporada no cotidiano de trabalho do SUS? Incorporar um tema significa incluir no discurso, ou nas práticas? Incluir no discurso garante sua efetividade em termos de ações cotidianas? A análise aqui empreendida ainda deixa margem para dúvidas a esse respeito.

Certamente, tais palavras (acolhimento-vinculo-acesso, vinculo-acolhimento, responsabilização etc.) são temas presentes no discurso dos profissionais que atuam no âmbito do SUS, sobretudo, na atenção básica, em função mesmo das políticas que preconizam o SUS. Esta incorporação está, todavia, provavelmente, presente no discurso dos profissionais em função da sua fala, captada pelo uso de entrevistas, técnica utilizada pelas pesquisas que examinamos. Mas até que ponto é possível afirmar que, por exemplo, acolhimento, vínculo e acesso sejam incorporados no cotidiano, se se tratam de três construtos teóricos distintos, ainda que nivelados, indistintamente?

As pesquisas que, em sua maioria, propóem-se a avaliar se esta ou aquela proposição, inserida nas políticas, ou em algum construto teórico, efetiva-se ou 
não, incorpora-se ou não, no âmbito dos serviços, não apresentam questionamentos sobre o que tem sido feito para que tais políticas sejam incorporadas. E se o que tem sido feito é válido no sentido desta incorporação.

O exercício da reflexividade se faz necessário quando buscamos compreender se o que tem sido feito tem alguma validade no sentido de incorporação desta ou daquela premissa ou princípio normativo no âmbito dos serviços de saúde. Para além da dimensão semântica, impóem-se consideraçôes de cunho metodológico. Isso porque a análise dos resultados das pesquisas examinadas, por vezes, não vai além da descrição, e a pergunta que fica silenciada é pensar até que ponto a realidade pode ser transformada mediante a elaboração de leis ou teorias que, automaticamente, as pessoas passa(riam) a seguir pelo simples fato de elas existirem como normas ou diretrizes.

Em geral, as falas presentes nos estudos que analisamos são apresentadas no sentido de revelar e/ou desvelar isso ou aquilo do fenômeno investigado. Os resultados parecem adotar um pressuposto ingênuo de que as falas/depoimentos dos sujeitos representam algo que existe concretamente na realidade, e raramente referem e/ou articulam o sistema de significados que o contexto daquela linguagem pode representar. Em suas análises, os estudos parecem tomar as falas do sujeito como um dado objetivo que revela, denota, confirma ou desconfirma isso ou aquilo.

Os estudos não esclarecem em que medida a linguagem é considerada e analisada como uma mediação, um sistema de significação próprio, ou um sistema abstrato cujo significado refletiria a realidade tal qual é. Em função disto, as constataçôes e/ou conclusôes daí resultantes apresentam limitaçóes nem sempre ponderadas.

Por outro lado, é preciso levar em conta também o alcance e limite dos instrumentos de pesquisa, como uma entrevista, em termos de adequaçáo ao fenômeno que se pretende investigar. Em que pese sua contribuição inequívoca para a pesquisa, uma entrevista guarda o pressuposto de que o sujeito entrevistado tenha um pensamento elaborado verbalmente sobre o que se fala. Sabemos que isso nem sempre é possível, sobretudo quando falamos de sentimentos ou valores. É preciso considerar os limites de quaisquer instrumentos para ter clareza em que medida contribui para elucidação de um objeto. 
A questão que se apresenta aqui é sobre a possibilidade de se analisar mudanças no cotidiano de trabalho dos profissionais de saúde somente em função do discurso, uma vez que as metodologias utilizadas na literatura examinada recorrem sempre a entrevistas e/ou grupos focais. É importante pensar que instrumentos ou técnicas (ou triangulaçóes dos mesmos) seriam necessários para captar ou compreender categorias complexas como o vínculo no contexto da atenção básica. O discurso (no sentido de produção verbal) de tais profissionais seria suficiente? Identificar a presença de tais palavras no discurso é, sem dúvida, algo importante. Entretanto, palavras como incorporar carregam diversas conotaçôes, cuja precisão de significado deve ser exposta com mais clareza e fundamentação epistemológica, ancorada em metodologias capazes de evidenciar tal "incorporação".

\section{Considerações finais}

Muitas perguntas são suscitadas quando elegemos o vínculo como fenômeno de investigação científica. Apesar de os estudos, no campo da Saúde Coletiva, espaço desta análise, constatarem sua inequívoca importância no campo da saúde, o vínculo quase sempre é algo não demarcado, mas que deveria existir como condição para funcionamento da atenção básica em termos de responsabilização e longitudinalidade do cuidado. Este lugar nebuloso certamente não significa $o$ lugar da não existência, mas, possivelmente, conforme procuramos evidenciar, uma lacuna a ser preenchida que se deve a um incipiente investimento conceitual ao que se soma uma inadequação dos métodos e técnicas de pesquisas utilizados ao focalizarem fenômenos relacionais tão complexos quanto o vínculo no campo da práxis em Saúde Coletiva, notadamente na atenção básica. ${ }^{1}$ 
Estudos localizados a partir dos descritores Atenção Primária à Saúde (APS), Atenção Básica à Saúde, Sistema Único de Saúde, Saúde da Família, Estratégia Saúde da Família, Saúde Coletiva e Saúde Pública

1. AlBUQUERQUE, R. A. et al. Produção do cuidado integral no pré-natal: itinerário de uma gestante em uma unidade básica de saúde da família. Interface (Botucatu), v. 15, n. 38, p. 677-686, 2011.

2. ALVES, G. G.; AERTS, D. As práticas educativas em saúde e a Estratégia Saúde da Família. Ciência e Saúde Coletiva, vol.16, n.1, p. 319-325, 2011.

3. AMORIM, A. C. C. L. A.; ASSIS, M. M. A.; SANTOS, A. M. Vínculo e responsabilizaçáo como dispositivos para produção do cuidado na Estratégia Saúde da Família. Revista Baiana de Saúde Pública. v. 38, n. 3, p. 539-554 jul./set. 2014.

4. ANTONACCI, M. H.; PINHO, L. B. Saúde mental na atenção básica: uma abordagem convergente assistencial. Revista Gaúcha Enfermagem, v. 32, n. 1, p. 136142, mar. 2011.

5. ARCE, V. A. R.; SOUSA, M. F.; LIMA, M.G. A práxis da Saúde Mental no âmbito da Estratégia Saúde da Família: contribuiçôes para a construção de um cuidado integrado. Physis: Revista de Saúde Coletiva. Rio de Janeiro, v. 21, n. 2, p. 541-560, 2011.

6. ARRUDA, C. D.; SILVA, M. G. V. Acolhimento e vinculo na humanização do cuidado de enfermagem as pessoas com diabetes mellitus. Revista Brasileira de Enfermagem. Brasília, v. 65, n. 5, p. 758 66, set-out. 2012.

7. BARATIERI, T.; MANDU, E. N. T.; MARCON, S. S. Compreensão de enfermeiros sobre vínculo e longitudinalidade do cuidado na Estratégia Saúde da Família. Ciencia y Enfermería, v. 18, n. 2, p. 11-22, 2012.
27. HINO, P. et al. The health needs and vulnerabilities of tuberculosis patients according to the accessibility, attachment and adherence dimensions. Revista Escola de Enfermagem USP, v. 45, n. esp. 2, p. 1656-1660, 2011.

28. IVA, C. S. et al. Controle pressórico e adesão/vínculo em hipertensos usuários da Atenção Primária à Saúde. Revista Escola de Enfermagem USP, v. 47, n. 3, p. 584590, jun. 2013.

29. JORGE, M. S. B. et al. Promoção da Saúde Mental - Tecnologias do Cuidado: vínculo, acolhimento, corresponsabilizaçáo e autonomia. Ciência Saúde Coletiva, v. 16, n. 7, p. 3051-3060, mar. 2011.

30. LAFAIETE, R. S.; MOTTA, M. C. S.; VILLA, T. C. S. User satisfaction in the tuberculosis control program in a city in Rio de Janeiro, Brazil. Revista Latino Americana de Enfermagem, v. 19, n. 3, p. 508-514. June 2011.

31. LIMA, L. L.; MOREIRA, T. M. M.; JORGE, M. S. B. Produção do cuidado a pessoas com hipertensão arterial: acolhimento, vínculo e corresponsabilização. Revista Brasileira de enfermagem, v. 66, n. 4, p. 514-522, 2013.

32. MARIN, M. J. S.; SANTANA, F. H.S.; MORACVICK, M. Y. A. D. Percepção de idosos hipertensos sobre suas necessidades de saúde. Revista Escola de Enfermagem USP, v. 46, n. 1, p. 103-110, fev. 2012.

33. MONTEIRO, M. M.; FIGUEIREDO, V. P.; MACHADO, M. F. A. S. Formação do vínculo na implantação do Programa Saúde da Família numa Unidade Básica de Saúde. Revista Escola de Enfermagem USP, v. 43, n. 2, p. 358-364, 2009. 
8. BARBOSA, G. B. et al. Trabalho e saúde mental dos profissionais da Estratégia Saúde da Família em um município do Estado da Bahia, Brasil. Revista Brasileira Saúde Ocupacional, v. 37, n. 126, p. 306-315, dez. 2012.

9. BARROS, R. S.; BOTAZZO, C. Subjetividade e clínica na atenção básica: narrativas, histórias de vida e realidade social. Ciência e Saúde Coletiva, v. 16, n. 11, p. 4337-4348, 2011.

10. BASTOS, L. S. et al. Construçáo da integralidade no cuidar de pessoas com diabetes mellitus em um centro de saúde em Feira de Santana (BA). Ciência e Saúde Coletiva, v. 16, supl. 1, p.1417-1426, 2011.

11. BERNARDES, A. G.; PELLICCIOLI, E. C.; MARQUES, C. F. Vínculo e práticas de cuidado: correlações entre políticas de saúde e formas de subjetivação. Ciência e Saúde Coletiva, v. 18, n. 8, p. 2339-2346, 2013.

12. BENEVIDES, R.; PASSOS, E. A humanização como dimensão pública das políticas de saúde. Ciência e Saúde Coletiva, v.10, n. 3, p.561-571, 2005.

13. BRUNELLO, M. E. F et al. O vínculo na atenção à saúde: revisão sistematizada na literatura, Brasil (1998-2007). Acta paulista de Enfermagem, v. 23, n. 1, p. 131-135, 2010.

14. BRUNELLO, M. E. F et al. Vínculo doente-profissional de saúde na atenção a pacientes com tuberculose. Acta Paulista de Enfermagem, v. 22, n. 2, p. 176-182, 2009.

15. CAMURI, D.; DIMENSTEIN, $M$. Processos de trabalho em saúde: práticas de cuidado em saúde mental na Estratégia Saúde da Família. Saúde e Sociedade, v. 19, n. 4, p. 803-813, dez. 2010.

16. CAPRARA, A.; RODRIGUES, J. A relação assimétrica médico-paciente: repensando o vínculo terapêutico. Ciência e Saúde Coletiva, v. 9, n. 1, p. 139-146, 2004.
34. MORAES, P. A.; BERTOLOZZI, M. R.; HINO, P. Percepçôes sobre necessidades de saúde na Atenção Básica segundo usuários de um serviço de saúde. Revista Escola de Enfermagem USP, v. 45, n. 1, p.19-25, 2011.

35. PINA, J. C. et al. Contribuiçôes da estratégia Atençáo Integrada às Doenças Prevalentes na Infância ao acolhimento de crianças menores de cinco anos. Acta Paulista de Enfermagm, v. 22, n. 2, p. 142-148. 2009.

36. PINHEIRO, P. M.; OLIVEIRA, L. C. A contribuição do acolhimento e do vínculo na humanização da prática do cirurgiãodentista no Programa Saúde da Família. Interface. Botucatu, v. 15, n. 36, p. 185198, 2010.

37. PINI, J. S.; WAIDMAN, M. A. P. Fatores interferentes nas açốes da equipe da Estratégia Saúde da Família ao portador de transtorno mental. Revista Escola de Enfermagem USP, v. 46, n. 2, p. 372-379, abr. 2012.

38. QUEIROZ, M. V.; JORGE, M. S. Estratégias de educação em saúde e a qualidade do cuidar e ensinar em pediatria: a interação, o vínculo e a confiança no discurso dos profissionais. Interface. Botucatu, v. 10, n. 19, p. 117-130, 2006.

39. ROCHA, P. M. et al. Avaliação do Programa Saúde da Família em municípios do Nordeste brasileiro: velhos e novos desafios. Cadernos de Saúde Pública, v. 24, supl. 1, p. 69-78, 2008.

40. SÁ, L. D. et al. Intersectorality and bonding in tuberculosis control in Family Health.

Revista Latino-Americana de Enfermagem, v. 19, n. 2, p. 387-395, abr. 2011.

41. SAMPAIO, J. et al. Ele não quer com camisinha e eu quero me prevenir: exposição de adolescentes do sexo feminino às DST/ aids no semiárido nordestino. Saúde e Sociedade, v. 20, n. 1, p. 171-181, mar. 2011. 
17. COELHO, M. O.; JORGE, M. S. B. Tecnologia das relaçôes como dispositivo do atendimento humanizado na atenção básica à saúde na perspectiva do acesso, do acolhimento e do vínculo. Ciência e Saúde Coletiva, v. 14, supl. 1, p. 1523-1531, 2004.

18. CORREIA, V. R.; BARROS, S.; COLVERO, L. A. Saúde mental na atenção básica: prática da equipe de saúde da família. Revista Escola de Enfermagem USP, v. 45, n.6, p. 1501-1506, dez. 2011.

19. CUNHA, E. M.; GIOVANELLA, L. Longitudinalidade/continuidade do cuidado: identificando dimensôes e variáveis para a avaliação da Atenção Primária no contexto do sistema público de saúde brasileiro. Ciênc. Ciência e Saúde Coletiva, v. 16, supl. 1, p. 1029-1042, 2011.

20. DE CARLI, R. et al. Acolhimento e vínculo nas concepçôes e práticas dos Agentes Comunitários de Saúde. Texto Contexto Enfermagem, Florianópolis, v. 23, n. 3, jul-set, p. 626-632, 2014.

21. FAQUINELLO, P.; CARREIRA, L.; MARCON, S. S. A Unidade Básica de Saúde e sua funçáo na rede de apoio social ao hipertenso. Texto Contexto Enfermagem, v. 19, n. 4, p. 736-744, 2010.

22. FIGUEIREDO, G. L. A. et al. Experiences of families in the immunization of Brazilian children under two years old. Rev. LatinoAm. Enfermagem, v. 19, n. 3, p. 598-605, June, 2011.

23. FONTANELLA, B. J.; SETOUE, C. S.; MELO, D. G. Afeto, proximidade, frequência e uma clínica hesitante: bases do "vínculo" entre pacientes com síndrome de Down e a Atenção Primária à Saúde? Ciência e Saúde Coletiva, v. 18, n. 7, p. 1881-1892, 2013
42. SANTOS, I. M. V.; SANTOS, A. M.

Acolhimento no Programa Saúde da Família: revisão das abordagens em periódicos brasileiros. Revista Salud Publica. Bogotá, v. 13, n. 4, p. 703-716, ago. 2011.

43. SANTOS, A. M. et al. Vínculo e autonomia na prática de Saúde Bucal no Programa Saúde da Família. Revista Saúde Pública. São Paulo, v. 42, n. 3, p. 464-470, jun. 2008.

44. SANTOS, A. M. et al. Experiência de clínica ampliada em odontologia na Universidade Estadual de Maringá. Revista Brasileira Educaçáo Médica, v. 36, n.1, supl. 2, p. 178-183, mar. 2012.

45. SANTOS, A. P. L.; LACAZ, F. A. C. Apoio matricial em saúde do trabalhador: tecendo redes na atenção básica do SUS, o caso de Amparo/ SP. Ciência e Saúde Coletiva. Rio de Janeiro, v. 17, n. 5, p. 1143-1150, maio 2012.

46. SCHIMITH, M. D. et al. Relações entre profissionais de saúde e usuários durante as práticas em saúde. Trabalho Educaçáo e Saúde, v. 9, n. 3, p. 479-503, 2011.

47. SCHIMITH, M. D.; LIMA, M. A. D. S. Acolhimento e vínculo em uma equipe do Programa Saúde da Família. Caderno de Saúde Pública. Rio de Janeiro, v. 20, n. 6, p. 1487-1494, 2004.

48. SILVA, A. C. M. S. et al. A Estratégia Saúde da Família: motivação, preparo e trabalho segundo médicos que atuam em três distritos do município de Duque de Caxias, Rio de Janeiro, Brasil. Revista Saúde e Sociedade, v. 19, n. 1, p. 158-169, 2010.

49. SILVEIRA, D. P.; VIEIRA, A. L. S. Saúde mental e atenção básica em saúde: análise de uma experiência no nível local. Ciência Saúde Coletiva, v. 14, n. 1, p. 139-148, 2009. 
24. GOMES, A. L. C.; SÁ, L. D. As concepçóes de vínculo e a relação com o controle da tuberculose. Rev. Escola de Enfermagem USP, v. 43, n. 2, p. 365-372, jun. 2009.

25. GOMES, M. C. P. A.; PINHEIRO, R. Acolhimento e vínculo: práticas de integralidade na gestão do cuidado em saúde em grandes centros urbanos. Interface. Botucatu, v. 9, n. 17, p. 287-301, 2005.

26. GONÇALVES, R et al. Avaliação da efetividade da assistência pré-natal de uma Unidade de Saúde da Família em um município da Grande São Paulo. Revista Brasileira de Enfermagem, v. 61, n. 3, p. 349-353, 2008.
50. SOUZA, K. M. J. et al. Abandono do tratamento de tuberculose e relaçóes de vínculo com a equipe de saúde da família. Revista Escola de Enfermagem USP, v. 44, n. 4, p. 904-910, 2010.

51. VIEGAS, S. M. F. et al. O cotidiano da assistência ao cidadáo na rede de saúde de Belo Horizonte. Physis: Revista de Saúde Coletiva. Rio de Janeiro, v. 20, n. 3, p. 769 784, 2010.

52. VILLA, T. C. S.; RUFFINO, N. A. Questionário para avaliação de desempenho de serviços de atenção básica no controle da TB no Brasil. Jornal Brasileiro de

Pneumologia, v. 35, n .6, p. 610-612, 2009.

Fonte: as autoras

\section{Referências}

BERNARDES, A.G.; PELLICCIOLI, E.C.; MARQUES, C.F. Vínculo e práticas de cuidado: correlaçôes entre políticas de saúde e formas de subjetivação. Ciência e Saúde Coletiva. Rio de Janeiro, v. 18, n. 8, p. 2.339-2.346, 2013.

BOFF, L. Saber cuidar - Ética do humano. Compaixão pela Terra. Petrópolis: Vozes, 2004.

BRASIL. Ministério da Saúde. Secretaria de Atenção à Saúde. Departamento de Atenção Básica. Política Nacional de Atenção Básica. Brasília: Ministério da Saúde, 2012. (Série E. Legislação em Saúde).

BRASIL. Ministério da Saúde. Secretaria de Atenção à Saúde. Política Nacional de Humanização da Saúde. Documento Base. 4. ed. Brasília: Ministério da Saúde, 2007.

BRUNELLO, M.E.F et al. O vínculo na atenção à saúde: revisão sistematizada na literatura, Brasil (1998-2007). Acta paulista de Enfermagem, v. 23, n. 1, p. 131-135, 2010.

MERHY, E.E. Saúde: a cartografia do trabalho vivo. 2. ed. São Paulo: Hucitec, 2005.

PICHON-RIVIÈRE, E. Teoria do Vinculo. 7. ed. São Paulo: Martins Fontes, 2007.

SCHIMITH, M.D et al. Relações entre profissionais de saúde e usuários durante as práticas em saúde. Revista Trabalho Educação e Saúde, v. 9, n. 3, p. 479-503, 2011.

SILVA JÚNIOR, A.G.; MASCARENHAS, M.M. Avaliação da atenção básica em saúde sob a ótica da integralidade: aspectos conceituais e metodológicos. In: PINHEIRO, R.; MATTOS, R. A. (Orgs.). Cuidado: as fronteiras da integralidade. Rio de Janeiro: Abrasco, 2004. p.241-57 


\section{Bibliografia consultada}

BOSI, M. L.M. Pesquisa qualitativa em saúde coletiva: panorama e desafios. Ciência Saúde Coletiva. Rio de Janeiro, v. 17, n. 3, p. 575-586, 2012.

BOSI, M.L.M.; GASTALDO, D. Construindo pontes entre ciência, política e práticas em saúde coletiva. Revista Saúde Pública [on-line], v. 45, n. 6, p. 1.197-1.200, 2011. ISSN 00348910 .

GASTALDO, D. Ensinando pesquisa qualitativa em saúde no Canadá: alguns avanços e novos desafios. In: CHAPELA, M.C.; SERAPIONI, M.; GASTALDO, D. Debatedores. Ciência e Saúde Coletiva [on-line], v. 17, n. 3, p. 587-594, 2012.

MENDES, E.V. A construção social da Atenção Primária à Saúde. Brasília: Conselho Nacional de Secretários de Saúde - CONASS, 2015.

MINAYO, M.C.S. Ciência, técnica e arte: o desafio da pesquisa social. In: MYNAIO, M.C.S. (Org.). Pesquisa Social: teoria, método e criatividade. 18. ed. Petrópolis: Editora Vozes, 2001.

MINAYO, M.C.S. O Desafio do Conhecimento: Pesquisa Qualitativa em Saúde. 9. ed. Revista e Aprimorada. São Paulo: HUCITEC, 2006.

\section{Nota}

${ }^{1}$ M.I.S. Barbosa participou da elaboração do projeto e sua fundamentaçáo teórica; do trabalho de campo; da análise e categorização do material empírico e redação das versóes preliminar e final do artigo. M.L.M. Bosi participou da elaboração do projeto e sua fundamentação teórica; orientação da análise e redação das versôes preliminar e final do artigo. 


\section{Bond: a problematic concept in the Collective Health area}

he relationship between professionals and people who use health services is an important issue within the scope of the SUS and acquires a special language in the National Primary Care Policy (PNAB) by the use of the word "bond". This article aims to focus on the semantic dimension of the use of the term "bond" in Collective Health, reviewing research and official texts of the sector policy that include it in its descriptors or point it as relevant in its results. We selected 52 articles in Lilacs and SciELO databases, including in the subject or title fields the word "bond", associating it with the descriptors: Primary Health Care, Basic Health Care, Single Health System, Family Health, Family Health Strategy, Collective Health, Public Health. We conclude that, although the studies refer to the term/concept noting its unequivocal importance in the field of health, bond is almost always something not seen, but that it should exist as a condition for the functioning of the service in terms of accountability and longitudinality of care. This place of invisibility certainly does not mean the place of non-existence, but of the theoretical-methodological precariousness concerning conceptions and designs of research that touch on such complex relational phenomena as this one in the field of Collective Health.

> Keywords: Collective Health; bond; primary care. 